initial torque is proportional to the area of thread within the bone; this would be reduced by the proposed shallow, wide pitch.

The proposed fully-threaded cannulated screw would retain the advantages of cannulation and provide adequate fixation of SUFE. It would reduce the difficulties of screw removal, with its associated morbidity and considerable incidence of failure.

No benefits in any form have been received or will be received from a commercial party related directly or indirectly to the subject of this article.

\section{REFERENCES}

Black J. Editorial: Does corrosion matter? J Bone Joint Surg [Br] 1988; 70-B:517-20.

Crandall DG, Gabriel KR, Akbarnia BA. Second operation for slipped capital femoral epiphysis: pin removal.J Pediatr Orthop 1992; 12:434-

Lehman WB, Menche D, Grant A, Norman A, Pugh J. The problem of evaluating in situ pinning of slipped capital femoral epiphysis: an experimental model and a review of 63 consecutive cases. $J$ Pediatr Orthop 1984; 4:297-303.

Stambough JL, Davidson RS, Ellis RD, Gregg JR. Slipped capital femoral epiphysis: an analysis of 80 patients as to pin placement and number. J Pediatr Orthop 1986; 6:265-73.

\title{
ISOLATED CAPITATOLUNATE COALITION: A CASE REPORT
}

F. C. ONER, H. R. DE VRIES

Carpal coalition, a common abnormality, usually produces no symptoms (Resnick 1988). Isolated coalitions involve bones in the same row, whereas syndrome-related coalitions may affect bones in different rows (O'Rahilly 1953; Poznanski and Holt 1971; Cope 1974). We present a case of coalition between the capitate and lunate, not associated with any known syndrome.

Case report. A 19-year-old man was referred to our department for evaluation of his dominant right wrist. There had been no history of trauma or inflammation. The range of motion had always been limited but it had never bothered him until he began a course on furniture-making.
On physical examination there was no visible deformity. Dorsiflexion of the right wrist was $30^{\circ}$ compared with $70^{\circ}$ on the left; palmar flexion on the right was $50^{\circ}$ and on the left $70^{\circ}$. Radial and ulnar deviation was the same on both sides.

Radiographs showed an irregularity between the trapezoid and the capitate which was interpreted as a possible incomplete coalition between these two bones (Fig. 1). Such a coalition would not explain the limitation of wrist motion. CT of both wrists with two-dimensional reconstruction (Fig. 2) revealed no bony coalition between the trapezoid and the capitate, but a bone bar between the

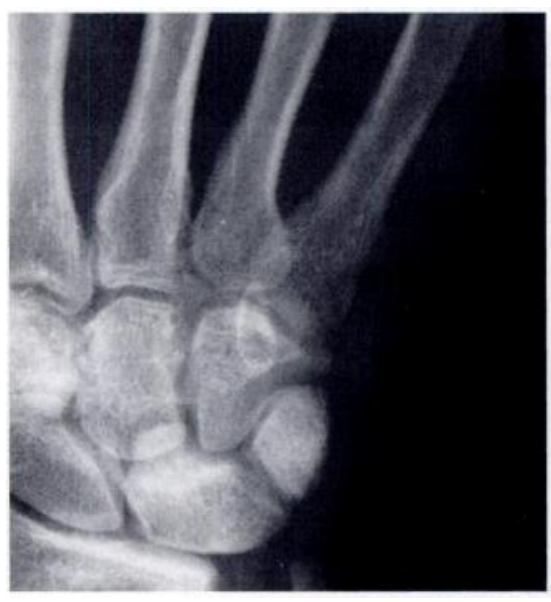

Fig. 1a
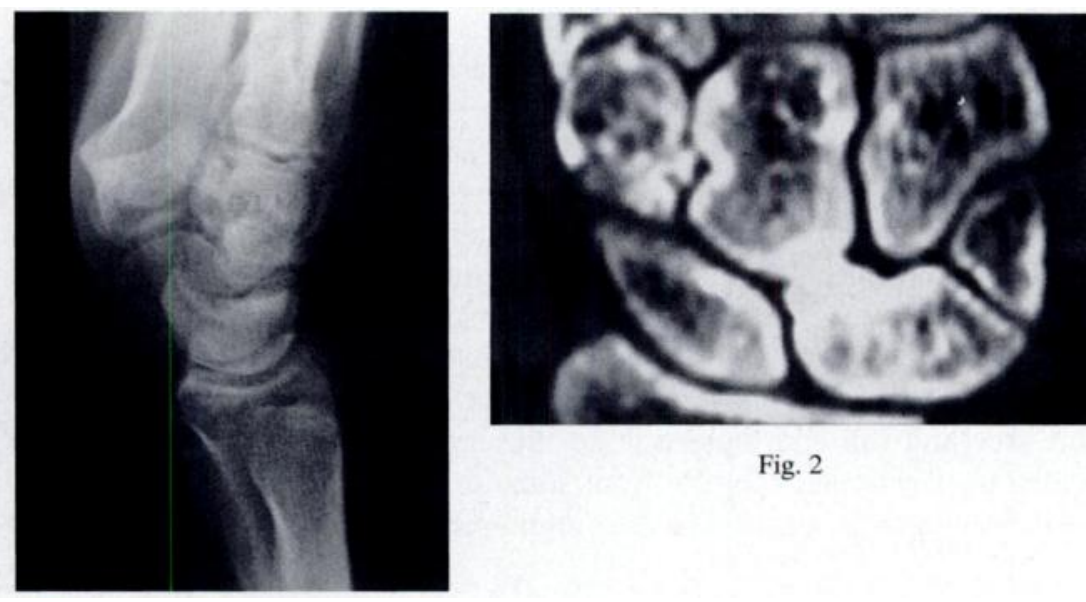

Fig. 2
F. C. Oner, MD, Senior Registrar

H. R. de Vries, PhD, Senior Registrar

Department of Orthopaedics, University Hospital, Dr Molewaterplein 40 3015 GD Rotterdam, The Netherlands.

Correspondence to Dr F. C. Oner at Department of Orthopaedic Surgery, University Hospital, PO Box 85500, 3508 GA, Utrecht, The Netherlands.

C1994 British Editorial Society of Bone and Joint Surgery 0301-620X/94/5R $10 \$ 2.00$

J Bone Joint Surg [Br] 1994; 76-B:845-6.

Received 23 August 1993; Accepted 8 October 1993 capitate and the lunate dorsally. This bony bridge was also seen on a three-dimensional reconstruction. The patient was satisfied with the explanation of his limited wrist motion and did not require treatment.

Discussion. Coalition between the capitate and the lunate, not associated with a syndrome of other deformities, is extremely rare. The only reference which we could find is in O'Rahilly (1953) who refers in turn to Kanavel 
(1932) on congenital malformations and to Meves (1938). An explanation of this apparent rarity may lie in the difficulty of imaging the carpus. In our case there was no suggestion of a bar between the capitate and the lunate on standard radiographs. The patient denied any severe trauma or inflammation and the radiological abnormality is unlike any known post-traumatic pattern. It resembles more the common tarsal coalitions in which there is also a bony bar. The irregularities between the trapezoid and the capitate may represent another congenital deformity or be secondary adaptive changes resulting from the abnormal pattern of carpal motion.
No benefits in any form have been received or will be received from a commercial party related directly or indirectly to the subject of this article.

\section{REFERENCES}

Cope JR. Carpal coalition. Clin Radiol 1974; 25:261-6.

O'Rahilly R. A survey of carpal and tarsal anomalies. J Bone Joint Surg [Am] 1953; 35-A:626-42.

Poznanski AK, Holt JF. The carpals in congenital malformation syndromes. Am J Roentgenol Radium Ther Nucl Med 1971; 112:443-59.

Resnick D. Additional congenital or heritable anomalies and syndromes. In: Resnick D, Niwayama G, eds. Diagnosis of bone and joint disorders. Second ed, Vol. 5. Philadelphia, etc: W. B. Saunders Co, 1988:3541-96.

\title{
THE NATURAL HISTORY OF CONGENITAL PSEUDARTHROSIS OF THE CLAVICLE
}

\author{
AVSHALOM SHALOM, OVED KHERMOSH, SHLOMO WIENTROUB
}

There is still some controversy about the management of congenital pseudarthrosis of the clavicle, with divergent views on the need for excision and bone grafting with or without internal fixation (Alldred 1963; Jinkins 1969; Gibson and Carroll 1970; Owen 1970; Quinlan, Brady and Regan 1980; Schnall, King and Marrero 1988) or of simple excision of the pseudarthrosis for cosmetic purposes (Alldred 1963; Grogan et al 1991).

This benign condition rarely produces any functional disability; numerous operative complications have been reported (Alldred 1963; Owen 1970; Toledo and MacEwen 1979; Grogan et al 1991) and it seems worthwhile to present a very long follow-up of one case to help to document the natural history.

Case report. A 45-year-old male right-handed ENT surgeon had congenital pseudarthrosis of the right clavicle diagnosed in infancy. There were no other congenital anomalies and no other members of his family had the condition. On examination, there was subcutaneous swelling in the right midclavicular region (Fig. 1) with no tenderness or pain on movement. Shoulder movements were free and full and there was no muscle wasting or weakness. Clavicular lengths from joint to joint were equal. Radiographs confirmed the mobile pseudarthrosis

Shalom, MD Intern in Medicine

O. Khermosh, MD, Senior Lecturer in Orthopaedics

S. Wientroub, MD, Professor of Orthopaedics

Department of Pediatric Orthopaedics, Dana Children's Hospital, Tel-Aviv Medical Center, 6 Weizmann Street, Tel-Aviv 64239, Israel.

Correspondence to Professor S. Wientroub.

(C)1994 British Editorial Society of Bone and Joint Surgery

0301-620X/94/5R $12 \$ 2.00$

J Bone Joint Surg [Br] 1994; 76-B:846-7.

Received 10 September 1993; Accepted 14 October 1993
(Fig. 2). There were no arthritic changes in the pseudarthrosis or in the acromioclavicular joint.

The patient is active, performs delicate operations and enjoys sports activities. He wants no treatment and finds the disability acceptable except for the appearance.

Discussion. In childhood, congenital pseudarthrosis of the clavicle does not disturb function and if the prominence

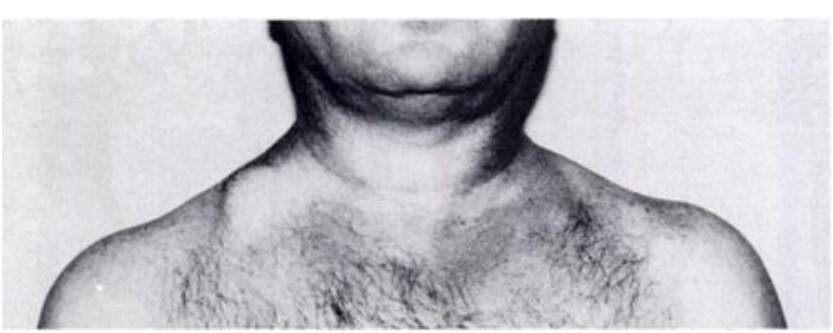

Fig. 1

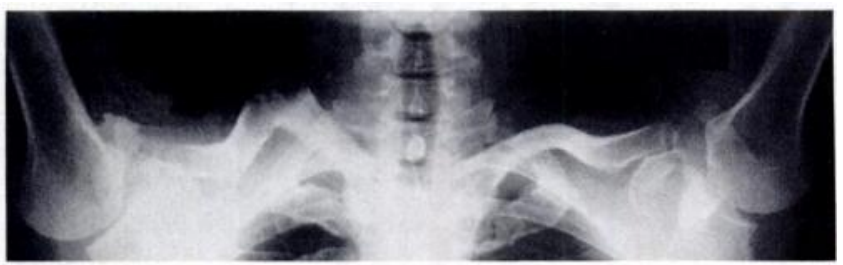

Fig. 2a

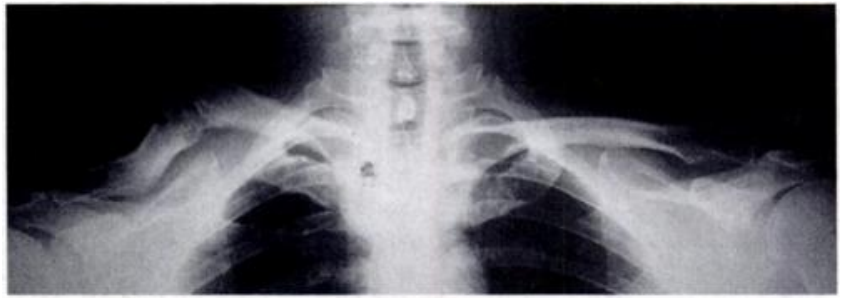

Fig. $2 b$ 